\title{
Evidencing Personal \& Professional Development, Perspective of a Surgical Trainee
}

\author{
A. Z. Kaleem*, N. Naheed, S. M. Ahmad \\ Scunthorpe General Hospital, North Lincolnshire \& Goole NHS Foundation Trust, Scunthorpe, UK \\ Email: *Ahmed.kaleem@nhs.net
}

Received 22 December 2015; accepted 22 March 2016; published 25 March 2016

Copyright (C) 2016 by authors and Scientific Research Publishing Inc.

This work is licensed under the Creative Commons Attribution International License (CC BY). http://creativecommons.org/licenses/by/4.0/

(c) (i) Open Access

\section{Abstract}

Introduction: The author strongly believes that there is a continuous need for personal and professional development in order to keep and improve an individual career path way. It is also imperative to provide evidence of these acquired skills and attributes. According to General medical council, it is a responsibility of every doctor to be competent and up to date. This should be achieved by regularly taking part in activities that maintain and further develop competence and performance. This in turn ensures safety and care to patients [1]. Methodology: The author has had excellent opportunities in his career to participate in diverse personal and professional development programmes. It was important to participate in these programmes to achieve career progression. He would like to share three recent activities from his curriculum vitae which resulted in his significant personal and professional development. The author also had his revalidation last year and found to be fit to practice for next 5 years till next revalidation. The author followed an agreed action plan with his supervisor to accomplish this work. Realistic goals and time frame was set with the help of supervisor. Subsequently, the author had a chance to critically analyse below mentioned three different activities, in order to explore all the achieved learning themes behind these events. The author was fortunate enough to be involved into three different personal and professional development programmes. Firstly, he managed a regional colorectal conference and attained an excellent management experience from that conference. He learnt a lot about better time management. He came to know about different management theories and models and is now able to use these theories for his future management responsibilities. Then he had a communication challenge and difficulty in theatre. He was able to resolve that issue with his strong communication skills. He developed his communication skills and assertiveness with the help of this first-hand experience and different communication models. Lastly, the author had a wonderful opportunity to demonstrate and develop his leadership and team working skills in an

${ }^{*}$ Corresponding author. 
International Conference. He realized that leader needs to be a role model for his team and should be leaded by his example. He observed and demonstrated different roles of a leader according to needs of his team. He also learnt about different leadership theories and models. He also acquired a good understanding of a team development. Conclusion: It is extremely important for every health care individual to have personal and professional development. The author recommends that lessons learnt from the author's experience and results can be applied in a broad generalised way to achieve development. It is crucial for us to keep a structured record of this development and provide evidence of the improvement. In short, it was an extremely useful exercise for the author that resulted in significant lifelong development in his management, communication and leadership attributes.

\section{Keywords}

Professional Development, Surgical Trainee, Individual Career, Revalidated

\section{Introduction}

Personal and professional development is vital in any career to attain progress. It is also paramount to provide proof of these acquired talents and traits. According to General medical council, it is a responsibility of every doctor to be competent and up to date. This should be achieved by regularly taking part in activities that maintain and further develop competence and performance. This in turn ensures safety and care to patients [1]. General medical council has also introduced the idea of revalidation in recent years to establish competence levels of existing doctors. It is now compulsory for all the doctors on GMC register to get revalidated once in 5 year to confirm expected knowledge and expertise. Therefore it is not only crucial for doctors to keep their skills and knowledge up to date but also imperative to provide evidence of their development in order to get revalidated.

The author was involved in diverse personal and professional development programs in his career which resulted in his professional progress. Three diverse developmental activities from the author's curriculum vitae are discussed in detail in this paper, which resulted in his significant personal and professional development. The author also had opportunity to critically analyze these educational activities in order to ensure that all the learning themes and objectives behind these events have been achieved.

\section{Management Activity}

The author has had an exceptional opportunity which involved management of a regional colorectal conference. This was a unique event held last year in my local hospital. Conference programme comprised of live operating theatre session, presentations, and preconference faculty dinner. The author was involved in all key stages of this conference management. The main responsibilities of the author were

- Programme settling,

- Inviting delegates and faculty member,

- Organizing preconference faculty dinner,

- Patient selection for live session and consent process,

- Live tele-link management,

- Live operating with supervisor,

- Oral presentation,

- Feedback assortment.

It was a very successful meeting with excellent feedback from attendees. The meeting was a true reflection of non-stop hard work of effective team managed by the author.

\subsection{Learning Theme and Analysis 1}

This was an excellent chance for the author to learn and demonstrate his management skills. It goes without saying that success in any event is not conceivable without effective management. The author believes that 
"Leadership is about hearts and minds, management is about nuts and bolts" [2]. Therefore effective manager plays a key role in stream lining all the involved processes and procedures in a project. It is his responsibility to deliver a structured thorough approach to complete a project. It is also his duty to provide comprehensive guideline to his team so that realistic goals can be achieved.

The author learnt that to be proactive as suggested by [3] is a fundamental skill to have in effective management. It is vital to be prepared and act at timely manner to get best results. The author also came to know that modified management model of Dr. Covey should be followed inactive management to get maximum efficiency. This model consists of the circle of control, influence and acceptance.

The initial model is somewhat like this (Figure 1).

According to Dr. Covey, the proactive people work hard in management on things which they can control and subsequently influence others. They do not waste time on the things they cannot control or influence and simply accept them. Hence in proactive people case because of better and effective management their circle of control and effect keep getting bigger and acceptance become smaller. In essence, they will have better control and can influence their team more by just being proactive as shown in Figure 2.

The author was also able to learn effective time management in that busy time. He recognised that effective time management is a prime skill to have for a successful manager. The author was able to achieve its set goal in timely manner because of this acquired skill. He was able to accomplish all his responsibilities in a set time frame.

The author used the below mentioned "The urgent VS Important matrix" originally designed by United States president Dwight Eisenhower (Table 1). US President used this time management model in the Second World War. This matrix was later adapted by Dr Covey who was author of "the 7 habits of highly effective people" which was a bestselling book in this context.

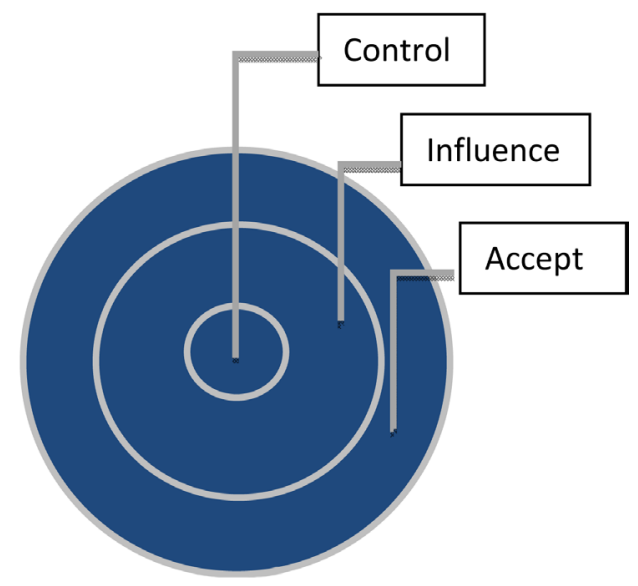

Figure 1. Covey management model.

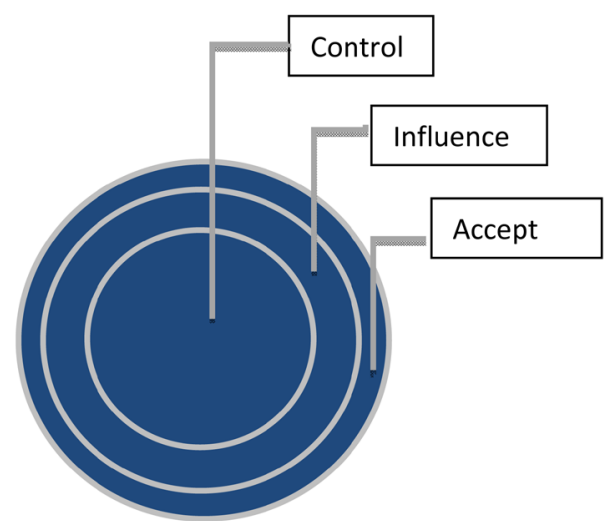

Figure 2. Covey modified management model. 
Table 1. Urgent versus important matrix.

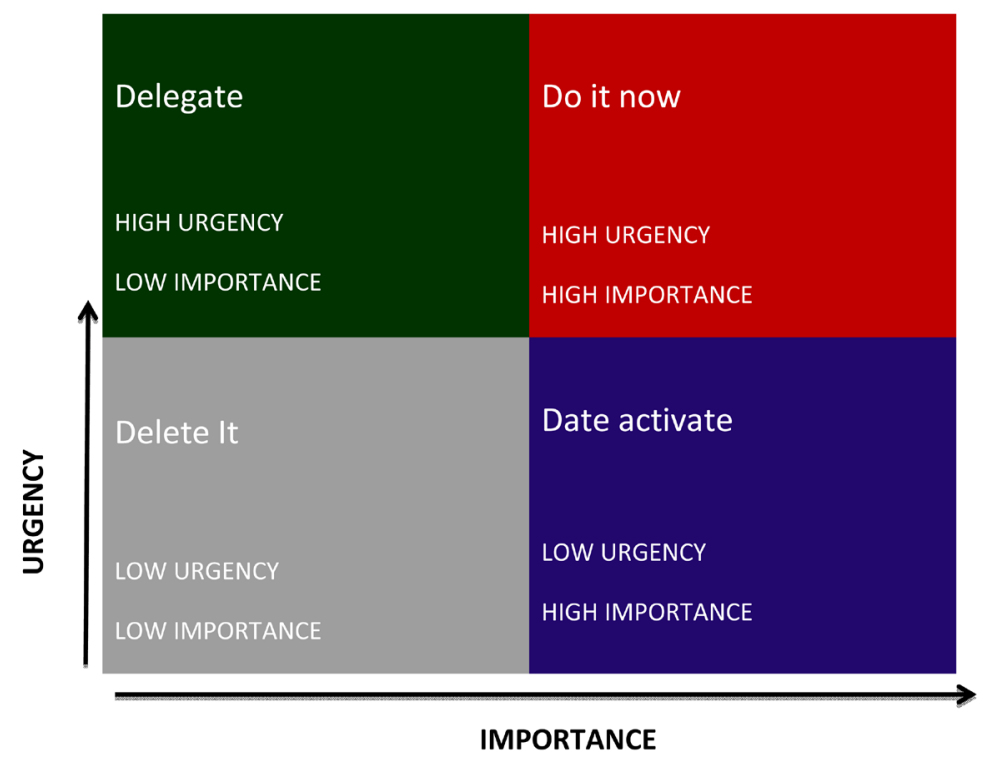

The author was able to achieve maximum efficiency in that limited time with this model. It is a good tool to organize important and urgent tasks. It gives clear direction and path to managers to adapt prioritization. The Author strongly recommends using the above mentioned tool to achieve effective time management.

The author also observed possible reasons which can potentially fail time management. This model which is called “The Logical Level/Iceberg model” [4] reflects the possible causes in this regard (Figure 3).

Groups are shown in a Pyramid in the above model. The main concept behind the pyramid is that each level is affected by the level below it. This effect can be either positive or negative. It is an important tool to discover the root cause of the problem in time management. I have learnt that it is imperative to have appropriate supportive environment and then positive behaviour of the individual to achieve real time management. Problem could be at the level of capabilities. Appropriate training plays an important role in this capabilities related problem. Some people fail time management due to their false beliefs. They need to believe in this fact first that time management is essential and can be done. Lastly, the sole problem could be at the level of individuality according to above mentioned level. Some people are confused and feel themselves hopeless in managing time; hence there arises a strong need of development and change at individual level.

The author has discovered during this conference that motivation plays a main role in effective management. It is paramount to be decisive and know the importance of work life balance .It is important to set realistic goals and then work accordingly to a set protocol to achieve these goals. [5] has given greatest tips on time management. According to him we should do the most boring or unpleasant work first and get it out of our way so that we can perform the enjoyable tasks later. Hence there is an incentive there, that after hardship we will be free to deal with delightful work.

\subsection{Communication Activity 2}

The author spend significant amount of his time in operating theatre. It is essential part of his job to perform operations both under supervision as well as independent depending upon the complexity of case. Therefore there is a diverse spectrum to learn from theatre atmosphere. Recently the author started learning new laparoscopic surgical procedure which is extremely beneficial for patients. The author had formal training first about that laparoscopic surgical procedure and then started performing under supervision. The author was initially slow but safe for obvious reason. He noticed that there was a continuous lack of support from operating theatre staff for that particular laparoscopic procedure only because it was time consuming. Theatre nurses and Operating theatre staff were unwelcoming to that new laparoscopic procedure.

The author observed this particular attitude. Most of the theatre staff members were under this false impression that this particular procedure with keyhole surgery was not worthwhile and carried no benefit to patient. Obviously there was an element of rejection to new technique. 


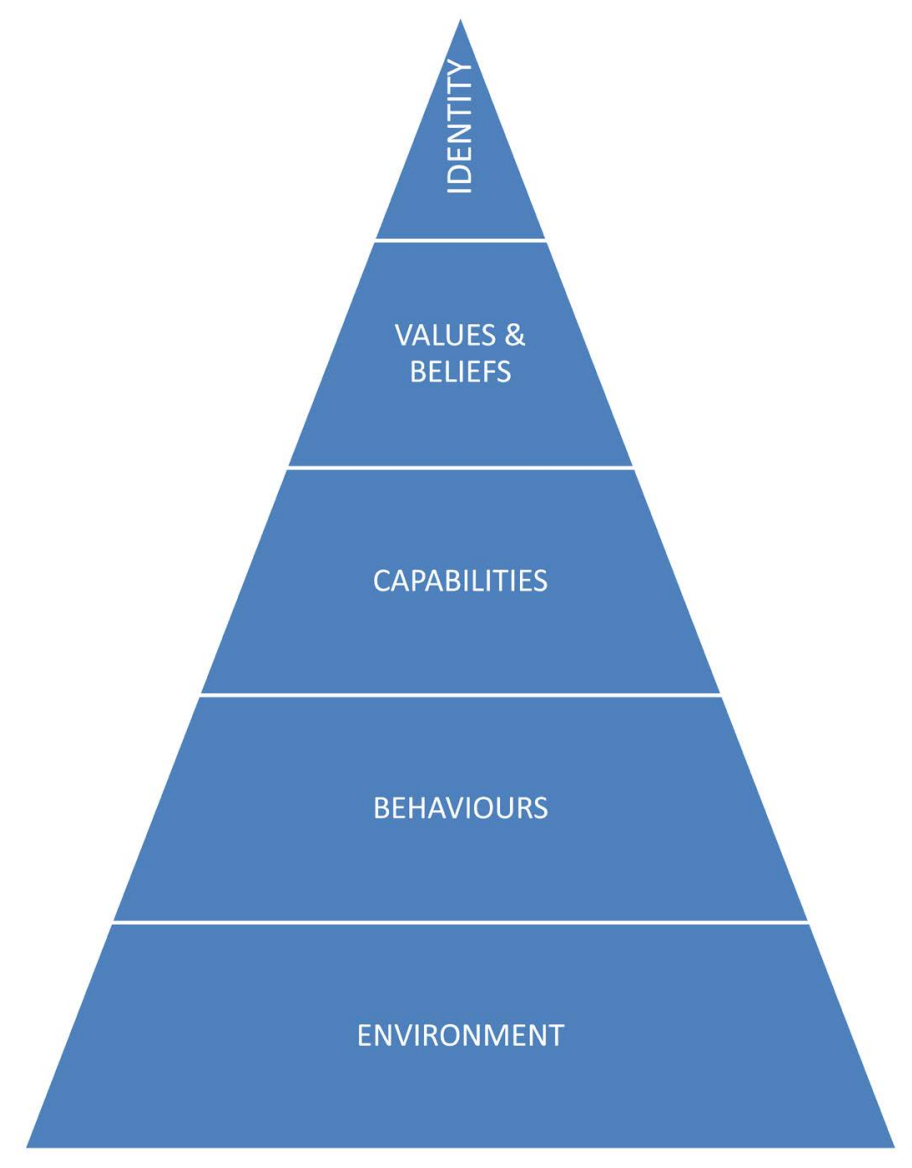

Figure 3. Logical levels.

The author realized that there was a strong need for awareness and education. He managed to solve this issue with assertiveness and with his communication skills. The authors demonstrated effective communication skills including active listening skills and assertiveness and soon theatre staff strongly realized about the good nature of this operation to patients. The author took few theatre staff member also to the ward to visit patients who has had this laparoscopic surgery. The theatre staff was pleasantly surprised after seeing patients after this surgery fully mobile next day rather than bed bound for few days post open procedure. This also gave theatre staff objective evidence and then there was an easy wide acceptance for that laparoscopic procedure.

Now there is an absolute change in culture in theatre and all of theatre staff has active interest for this particular laparoscopic procedure. Theatre staff would like this procedure to be performed laparoscopically at majority of the time. The author believes that all patients are different and has got different needs. Some patients are not suitable for laparoscopic procedures. Now the staff would always like to know the reasoning behind an open traditional technique when it is used on that rare occasion to meet individual patient need. This is a true recognition and reflection of the author communication skill which lead to the acceptance of this particular laparoscopic procedure. Obviously with time and experience, the author is also able to perform this procedure quickly and able to teach others.

\section{Learning Theme and Analysis}

The author had a wonderful experience in that challenging time to learn and demonstrate effective communication skill with the help of assertiveness. The author believes in the work of [6] in this regard, who was a leading psychologist and concluded that communication can be sub grouped in to 3 elements

- Words,

- Tone,

- Body language. 
These 3 elements have different weight age and effect in overall communication as mentioned in Figure 4.

It is clearly mentioned that body language carries leading role in communication and constitutes $55 \%$ of overall effect in this process. Words only play 7\% role in contrary, although important but have less significance than body language and tone respectively.

The author used all these different elements according to its effect in his communication in the above mentioned scenario. It is my personal experience that body language carries an major impact in all the difficult communication scenarios. We need to stress more in words in written language as this lack in emotions and tone. Extra attention is also paid in tone and words in telephonic conversation as it lacks emotions as well and it is important to bridge that communication gap. Therefore, it is crucial to have appropriate body language with emotions at all times. This will eventually help in acquiring clear and accurate tone. Then words should also be carefully chosen to relay message across effectively. The author has now learnt that if proper body language along with accurate tone and appropriate words is used, then communication always become a delightful success story.

The author has also learnt about Eric Berne's transactional analysis [7] based on effective communications during the above mentioned theatre scenario. According to the analysis, each person is made up of three following different ego states in communication (Figure 5).

\section{Parent}

This is a taught idea of life. It is our acquired voice of authority and command which is learnt over time. It can be reflected in physical way by impatient body language, finger pointing, patronising gestures etc. Verbally it is manifested words like always, never, posturing language etc.

\section{Adult}

This is a thought model of life. It is an ideal communication ego state. This stage is acquired by our ability to think and respond accordingly. It is a balanced stage which is reflected physically by attentive, interested, straight forward, non-threatening behaviours. It is shown verbally with the help of words like I think, I see, I realise, in my opinion etc.

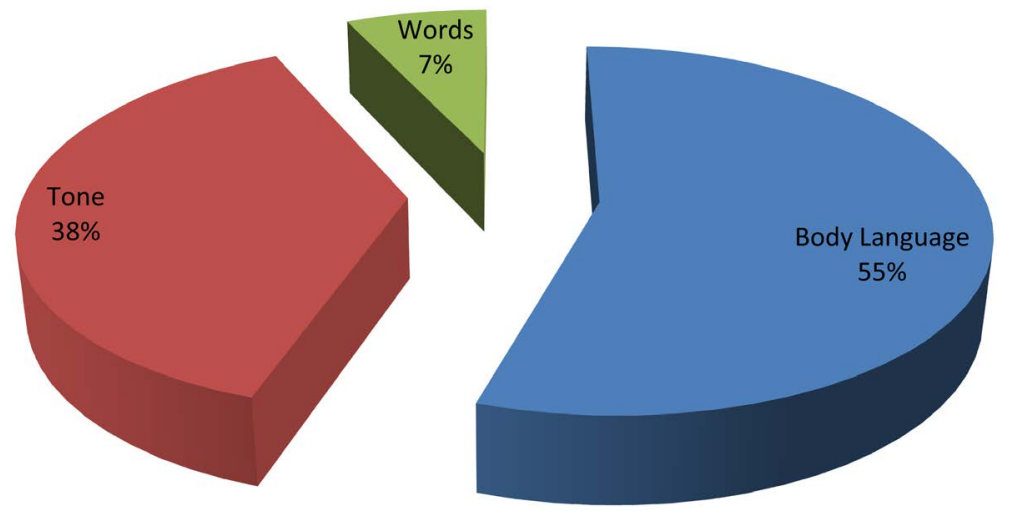

Figure 4. Mehrabian communication chart

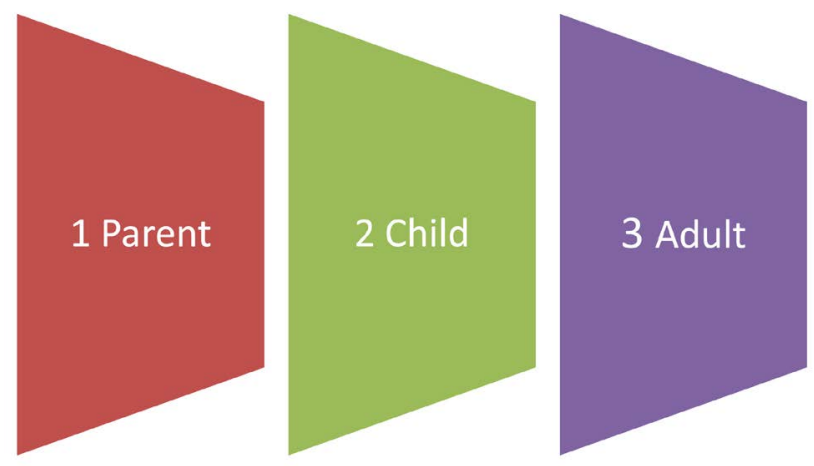

Figure 5. Eric Berne’s transactional analysis. 


\section{Child}

It is a felt concept of life. It is physically evident by attitudes like rolling eyes, teasing, shrugging shoulders and giggling etc. Verbally expression like I do not care, I do not know, baby talk is indication of child ego.

The author has learnt over time that although we all go through these above mentioned communication phases at times but it is best to have adult mode of communication to have meaningful and successful communication. Adult communication ego stage is a result of a balanced thoughtful approach and always leads to flawless communication. This also happened in the above mentioned scenario of communication, and with the help of this balanced adult approach, the author was able to achieve all the help and support from the theatre staff.

The author also gathered that it is also important to follow Wagner, Joines and Mountain (1980) modified model of communication mentioned by [7]. According to this model parent and child stage is further divided in to sub groups as shown in Figure 6 and Figure 7.

This remained a single entity.

The above mentioned model stressed upon the fact that although it is important for effective communication to be in adult ego state but it is equally important for a communication to be positive, in case child or parent mode is used. It is natural to go through the different ego stages of communication by default. Now the author has learnt that as long as communication is going through the positive sub group or if it is adult phase, then this process will always lead to a fruitful effective communication.

The above mentioned scenario also was an opportunity for the author to learn and reflect assertiveness. It is a pillar of communication and an essential life skill to have for all successful managers. The author has learnt that it is a weakness to have aggressive or passive behaviour. There is a fine balance between aggressiveness and assertiveness. It is also a fault in communication to demonstrate a passive behaviour. Assertive behaviour should be used to request others as well as in case of refusing the request. [8] suggested that limiting beliefs should be challenged to be assertive. By default we all have these above mentioned beliefs which stop us making the progress.

The author successfully learnt the art of assertiveness. He realized that it is not enough only to say no when one wants to say no but it is equally important to provide alternative if possible. It is also vital to explain at timely manner. He was also able to learn the skill to tackle aggressive and passive behaviour at that time. He observed that it is vital to be patient initially to ascertain others point of view and then reflect accordingly.

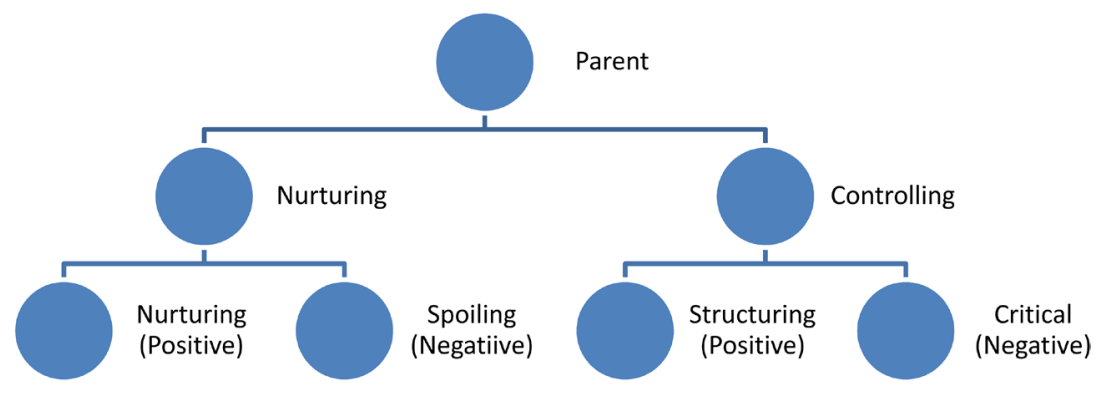

Figure 6. Modified model of communication.

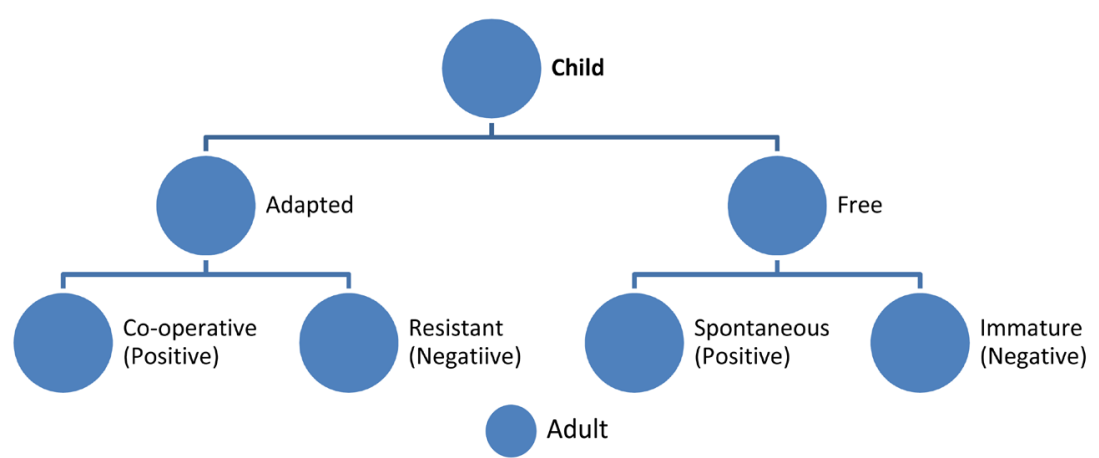

Figure 7. Modified model. 


\section{Leadership Activity}

The author also had an opportunity to be actively involved in The 3rd International Laparascopic \& Robotic TME symposium Portsmouth. It was an exclusive opportunity for the author to learn and demonstrate his leadership skills. This was a yearly event which held in Southampton. The author was responsible to lead a skilled team who was overlooking all the major arrangements of the conference. It was a 3-day conference where delegates came all over the world. The event programme included live operating theatre, teaching sessions, faculty lectures, poster exhibition etc. That conference was a successful event and it was only possible due to a dedicated team facilitated by the author with his leadership skills.

\subsection{Learning Theme and Analysis}

That above mentioned international conference was a source of significant development in the author's leadership and team working skills. The author learnt that there are some striking qualities in a leader which differentiate him from the rest of his team. These qualities which are mentioned below are essential to have for any successful leader (Table 2).

The author believes that "the overriding function of management is to provide order and consistency, whereas the primary function of leadership is to produce change and movement" [9]. Therefore successful leaders in any organization strive to deliver change. Although there appears to be a distinction between managers and leaders but the author has learnt that in real world frequently leader has to manage as well and vice versa. Leaders are blessed with unique quality of being creative. This quality differentiates them from managers.

Furthermore the author understood that "managers are people who do things right and leaders are people who do the right things” [10]. It means that leader always bring the right change and culture in his organization.

The author also observed during his leadership time that it is important for a successful leader to follow GROW model for coaching and providing leadership of his team, which is created by Sir John Whitmore in 1970 [11] (Figure 8).

According to above mentioned Grow model, it is desirable for a leader to have specific goals for his team. These goals should be realistic and measurable. It is also essential that there should be a time restriction set to achieve this aims. These set targets should be based on reality and achievable. The leader needs to utilise all the available options and should be well familiar with trouble shooting. The leader should also ensure that the systems and processes are in place to track the progress.

The author also learnt about team development and team behaviour over time during that period. Dr Bruce Tuckman Model explains this in an elegant way. According to [12], teams usually go through following phases and stages in their development (Figure 9).

Table 2. Qualities of a good leader.

\begin{tabular}{|c|c|}
\hline QUALITY & EXPLANATION \\
\hline Clear objectives & Leader should have a clear vision and strategy \\
\hline Inspiring role model & He should lead by his example \\
\hline Competent & There is no room for competency related issues \\
\hline Honest & He should be trust worthy and honest \\
\hline Flexible & Flexibility is important quality to have for a leader \\
\hline Respectful & He should be respectful to every body \\
\hline Team contributions & It is crucial to value others contribution \\
\hline Consistent & He should be consistent \\
\hline Fair & Always should be fair in his all dealings \\
\hline Hard working & Successful leader is always hardworking \\
\hline Assertiveness & He should be clear, polite and firm \\
\hline Communicator & He should possess excellent communication skills \\
\hline
\end{tabular}




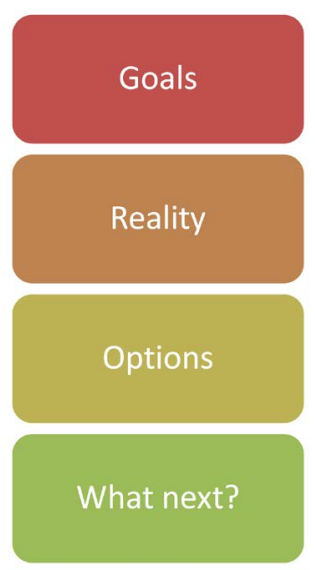

Figure 8. Grow model.

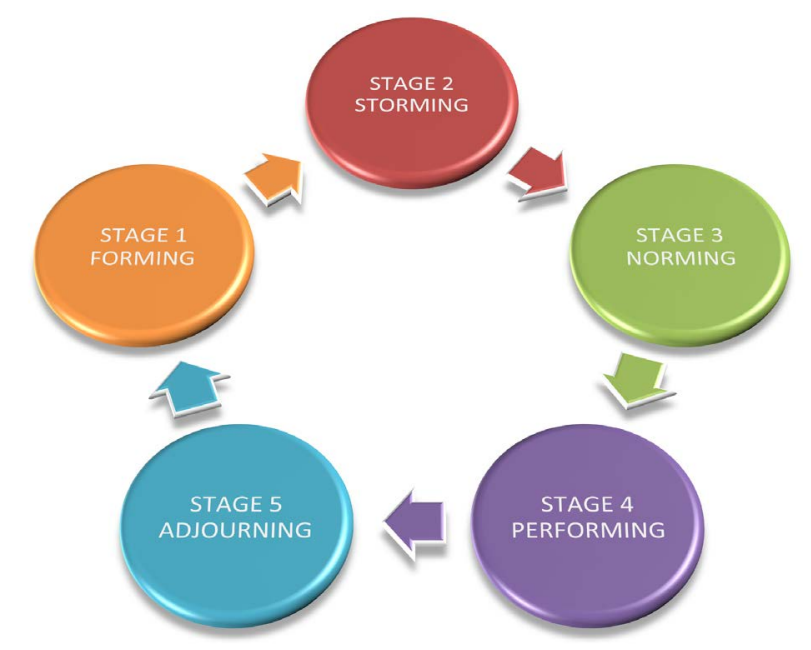

Figure 9. Tuckman’s teams stages.

\section{Stage 1}

This is the initial forming phase and leader provides clear direction at this stage in forming a team. This stage acts as foundation for effective performance of a team.

\section{Stage 2}

The leader provides a clear vision and goals in this storming stage so that team will not get distracted.

\section{Stage 3}

Leader only facilitates at this norming stage and let team members take responsibility.

\section{Stage 4}

Leader only oversees a team at this performing level. The team decides about its day to day work and activity. This is a peak level stage in team development.

\section{Stage 5}

This is a destructive stage called as adjourning stage. This is also referred as mourning stage and soon after this phase cycle restart from forming again with that active involvement of leader.

The author was able to witness most of these stages at that time. He was fortunate not to have mourning stage in his team during his leadership.

The author also noticed at that time that every individual in a team has different skills, willingness to work and competency levels. This observation led to the idea that although they are in the same team but they all have different needs. These needs are mainly based on their acquired skill and willingness to work.

Therefore the author learnt and used the idea of The Skills/ Will matrix [13] which is described below: 


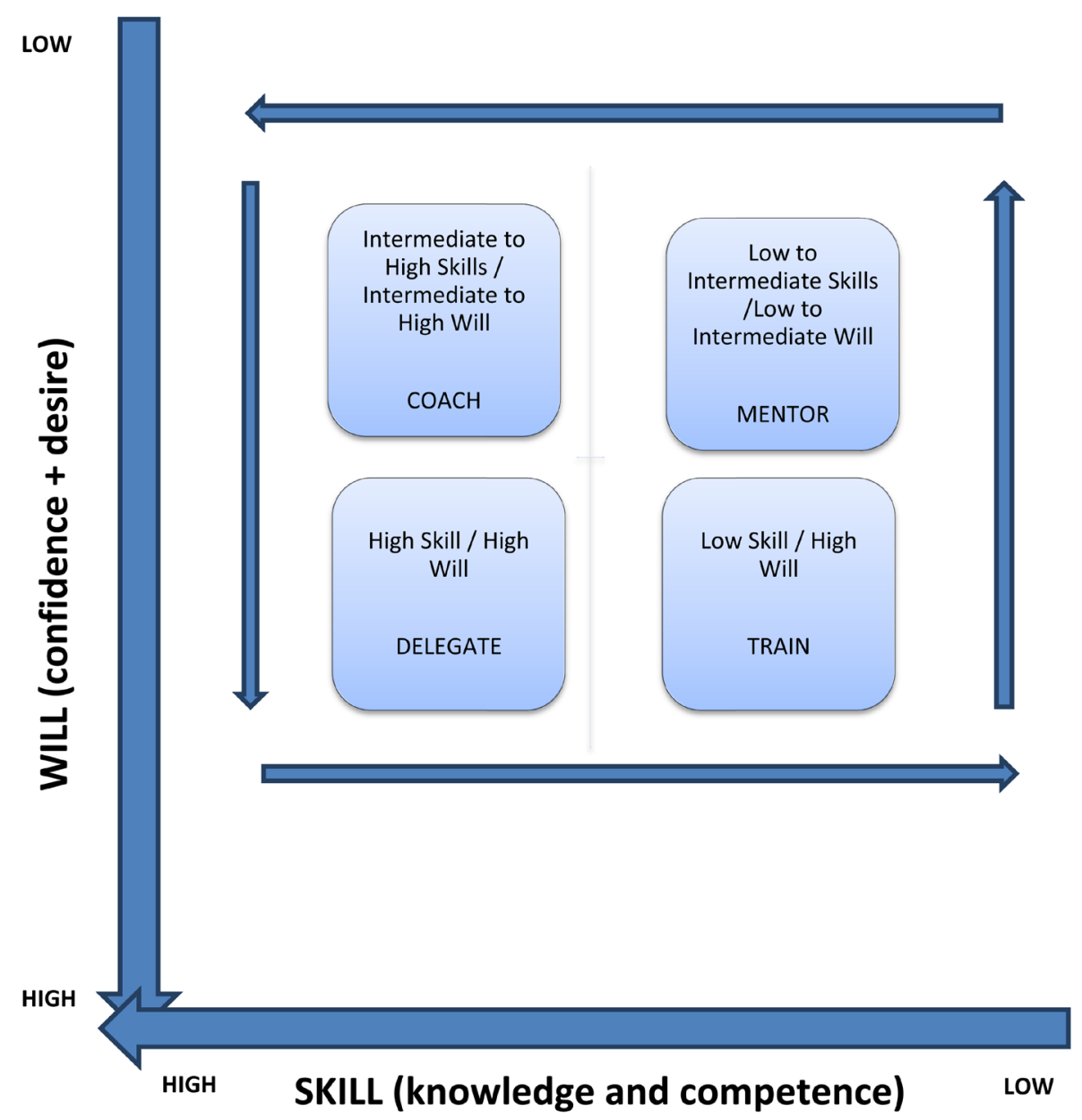

According to this matrix, leader in a team provides following four responsibilities depending on skill and will of his team worker (Figure 10).

This is also noted that skill does not only include knowledge but also involves competence level. In the same way will include both confidence and desire. Therefore according to above mentioned Skill/Will matrix, team worker can be divided into following four groups and needs accordingly.

1. Low skill/High will

This group of team members requires training and mentoring by the leader. They are new in their job but not lack of ambitions hence proper training of this group can lead to an effective successful team. They eventually become high skill and high will member because of their effective training.

2. Low/Intermediate skill + Low/Intermediate will

This group is already in their job for some time but not performing well because of multiple jobs related problems. There is strong need for proper support for this group by leader. Appropriate coaching by a leader can turn this group to a well performing group.

3. Intermediate/high skill + Intermediate/High will

These team members are in their jobs for significant times and have achieved success in the past but now are struggling. Therefore they require good coaching and right guidance

4. High skill/High will

This group is generally consists of role models with clear focus and vision. They provide positive results at all times. This group only requires minimum support from their leader and can also be delegated to provide support and help to above mentioned group 1.

The author was able to allocate his team members in appropriate groups and was able to provide appropriate support according to their needs. Therefore he was able to achieve maximum efficiency with minimum disruption with his leadership and team working skills. 


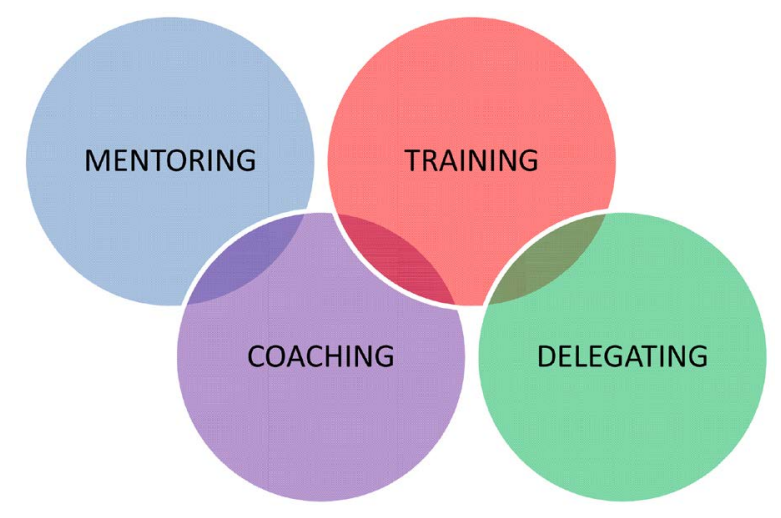

Figure 10. Leader roles.

The author now strongly believes that "Leadership is about hearts and minds, management is about nuts and bolts" [14] after that above mentioned fascinating experience gained during that International conference.

\subsection{Action Plan for Future Personal \& Professional Development}

It is imperative to find out self-deficiencies in order to achieve development. The author ultimately aspires to be a leading colorectal surgeon. It is necessary for a colorectal surgeon to be fully competent and expert in endoscopic skills. The author realized in the past that he was lacking in his endoscopic skills. It was also revealed from a gap analysis which was a self-assessment performed by the author. A gap analysis [15] is a comparative study, performed to establish deficiencies in performance. There was a strong need in this context which was appreciated by the author and a structured action plan was created. The author has used SOAR model suggested by [16] to set, analyse realistic goals and to formulate a structured plan to achieve these goals (Figure 11).

According to the above mentioned model, it was important to stress on different aspects in myself first. Motivation plays a leading role in this aspect. This is a strong reflection of willingness and my desire to develop myself in endoscopy. Then ability to achieve set targets in relation to personality come in this context. It is crucial to set realistic goals to attain these set targets. Subsequently the role of right opportunities and real aspiration come, which lead to a desired result in the shape of development.

The author structured plan included the following four steps. He is able to successfully complete a course and carry out an appraisal meeting. It means that he has already completed two out of four steps in order to gain the preferred future development. Theoretical and practical learning is still in progress (Figure 12).

\section{Course}

The author realized the importance of training in this context. He attended Basic skill in colonoscopy course to get real insight and proper training of endoscopy. This course provided him with the foundation and was also the opportunity for the author to reflect his real interest in endoscopy for his upcoming appraisal meeting.

\section{Appraisal Meeting}

Subsequently, the author had his appraisal meeting with clinical supervisor to discuss and formulate a plan to achieve desired outcomes. It was mutually agreed in that meeting, to have opportunity for the author for formal theoretical education and to provide practical learning. It was also agreed for the author to be fully supported for MSC GI Endoscopy programme and have training list.

\section{Theoretical Learning}

The author is now enrolled in MSC GI Endoscopy with the Hull University, which is currently in progress, in order to improve theoretical education and learning.

\section{Practical Learning}

The author is also attending named training list every week to develop his practical endoscopic skills.

In summary the author wishes to improve his endoscopic skills for his future development and a structured plan is already in progress to achieve this desired outcome. 


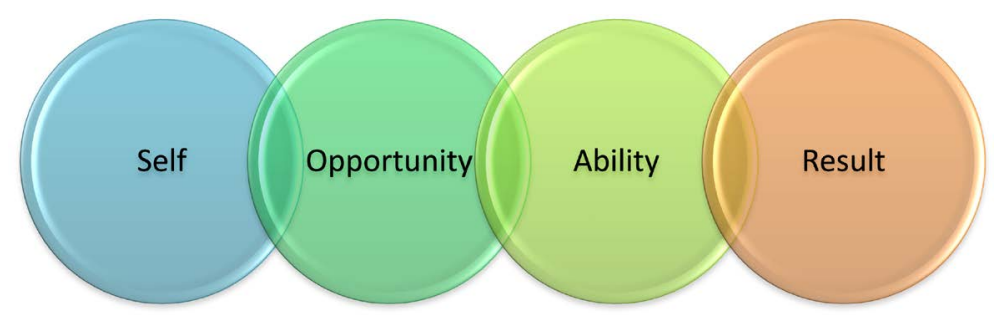

Figure 11. SOAR.

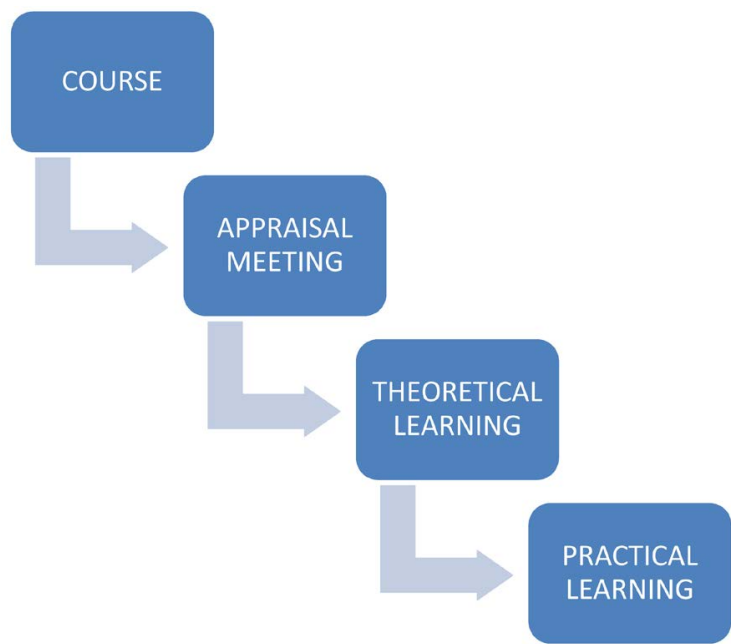

Figure 12. Future development steps.

\section{Conclusion}

In summary, it is extremely important for every health care individual to have personal and professional development. It is crucial for us to keep a structured record of this development and provide evidence of the improvement. The author was privileged to be involved in to different personal and professional development programs. He acquired an excellent management experience from organization of a regional conference. He learnt and developed his communication skills from a communication challenge. Lastly, the author attained significant development in his leadership and team working skills from an International Conference. He realized that leader needs to be a role model for his team and should lead by his example. He was able to get familiarized with different communication, leadership and management theories. He also had better understanding of different models based on these theories. In short, it was an extremely useful exercise for the author that resulted in significant lifelong development in his management, communication and leadership attributes.

\section{References}

[1] GMC (2012) Continuing Professional Development. http://www.gmc-uk.org/Continuing_professional_development_guidance_for_all_doctors_1114.pdf_56438625.pdf

[2] Blanchard, K.H., Zigarmi, P. and Zigarmi, D. (2013) Leadership and the One Minute Manager: Increasing Effectiveness through Situational Leadership. William Morrow, New York.

[3] Covey, S.R. (1989) The 7 Habits of Highly Effective People: Powerful Lessons in Personal Change. Free Press, United States.

[4] Dilts, R. (2006) Sleight of Mouth: The Magic of Conventional Belief Change.

[5] Tracy, B. (2004) Eat That Frog! Get More of the Important Things Done, Today!

[6] Mehrabian, A. (1970) Tactics of Social Influence.

[7] Berne, E. (2010) Games People Play: The Psychology of Human Relationships.

[8] Back, K. and Back, K. (2005) Assertiveness at Work: A Practical Guide to Handling Awkward Situation. 
[9] Kotter, J.P. (2008) A Sense of Urgency.

[10] Nannus, B. and Bennis, W.G. (2007) Leaders: Strategies for Taking Charge. 2nd Edition, Harper Collins Publisher, New York.

[11] Whitmore, J. (2009) Coaching for Performance: Growing Human Potential and Purpose-The Principles and Practice of Coaching and Leadership. 4th Edition, Nicholas Brealey Publishing, London.

[12] Tuckman, B. (2001) Developmental Sequence in Small Groups. Group Facilitation: A Research and Applications Journal, 71-72.

[13] Landsberg, M. (2003) Tao of Coaching: Boost Your Effectiveness at Work by Inspiring and Developing Those around You. Profile Books Ltd., London.

[14] Hersey, P., Blanchard, K.H. and Johnson, D.E. (2007) Management of Organizational Behavior: Leading Human Resources.

[15] Schellinck, T. and Brooks, M.R. (2014) Improving Port Effectiveness through Determinance/Performance Gap Analysis. Maritime Policy \& Management, 41, No. 4. http://dx.doi.org/10.1080/03088839.2013.809632

[16] Kumar, A. (2007) Personal, Academic and Career Development in Higher Education Soaring to Success. Routledge. 